\title{
PROYECTO DE COOPERACION MUNICIPAL CON LA REPUBLICA DEL PARAGUAY.
}

\author{
POR
}

\author{
Pedro antonio Martin Peréz. \\ SeCRETARIO de AdMINISTRACION LOCAL \\ Y COLABORADOR DE LA UNION DE CIUDADES \\ Capitales Iberoamericanas (U. C. C. I.).
}

Esta modesta aportación de "Bases para un proyecto de cooperación jurídico municipal con la República del Paraguay", nace de las ideas que surgieron tras la visita que efectué a la República del Paraguay entre el 26 de febrero y el 9 de marzo de 1990, a instancias de la Unión de Ciudades Capitales Iberoamericanas (U. C. C. I.) y de la racionalización e intelectualización de las mismas, una vez concluida la misión que efectué en aquel país hermano y dados los estelares momentos por los que deviene en la actualidad el Municipalismo Paraguayo.

El presente informe-trabajo contiene opiniones del que suscribe, inspiradas en impresiones personales y en un breve estudio del Derecho Municipal Paraguayo durante el tiempo que duró mi estancia en Asunción; opiniones que no podrán coincidir con las de la Organización por la que fui comisionado y están basadas en los principios valedores de la solidaridad cultural y en el estímulo de la hermandad hispano-paraguaya.

Estas bases pudieran servir de pauta para inspirar un proyecto de cooperación jurídica y municipal hispano-paraguaya, dentro de un posible Tratado General de Cooperación entre España y la República del Paraguay.

INDICE: I.- INTRODUCCION. II.- COOPERACION INTERMUNICIPAL ENTRE PAISES HISPANICOS. III.- EL MUNICIPALISMO PARAGUAYO Y ESPAÑOL: HISTORIA COMUN. A. Breve historia del Municipio en España. Etapa preconstitucional. B. Origen jurídico inmediato que configura la organización del Primer Cabildo Paraguayo. Las Ordenanzas de Carlos V de 1523. IV.- AlguNAS CONSIDERACIONES PARA PROPICIAR UN PROYECTO DE COOPERACION MUNICIpal con la Republica del Paraguay. V.- Algunas consideraciones en torNO A LA AUTONOMIA MUNICIPAL. SIGNIFICADO DE LA AUTONOMIA MUNICIPAL EN 
IBEROAMÉrICA. A. Contenido esencial de la autonomía municipal. VI.ESTUDIO COMPARATIVO DE LA EVOLUCION LEGISLATIVA LOCAL HISPANO-PARAGUAYA. A. Evolución legislativa local paraguaya. B. Evolución legislativa local española. VII.- DISPOSICIONES LEGISLATIVA MUNICIPALES EN VIGOR Y RElacionadas con la Ley № 1294, Organica Municipal del Paraguay. VIII.Legislacion local Vigente en EsPaña en la actualidad. IX.- Aspectos CONCRETOS EN LOS QUE SE DETERMINA LA COOPERACION ESPAÑOLA EN MATERIA MUNICIPAL. A. Propuestas concretas. $X$.- Algunas ReFleXIONES EN tORNo a LAS futuras modificaciones legislativas locales en la Republica del ParaGUAY. ANEXOS I.- Legislación iberoamericana básica. II.- Legislación europea municipal.

\section{I.- INTRODUCCION}

Las reformas democráticas instauradas en la República de Paraguay van a afectar, de una manera sustantiva, al panorama legislativo municipal de aquel pais, y al rol que le corresponde al Municipio en un sistema de inspiración en principios democráticos de representación popular.

En estos días se ha venido discutiendo en el Poder Legislativo el nuevo código electoral que fue remitido al Poder Ejecutivo para su correspondiente promulgación, que seguramente se ha llevado a efecto en la segunda quincena del mes de marzo.

La reforma de la Ley electoral y la conclusión del nuevo padrón comicial, constituyen un paso decisivo para apuntalar el cambio democrático en aquel país hermano. De no fijar u omitir el nuevo texto electoral la fecha de las próximas elecciones municipales, tendrán que ser fijadas por el Poder Ejecutivo a través de un decreto-ley. De acuerdo con los plazos establecidos en la Ley 886 , las elecciones municipales deberían realizarse el presente año, si bien todas las fuerzas políticas y sociales están de acuerdo en prolongar el plazo ordinario estipulado en aquella Ley para que se concluya el nuevo padrón, apuntándose los meses de febrero o abril del año que viene.

Existe una avezada tradición municipalista en el Paraguay que se reafirma, en opinión del ilustre legislador J. Augusto Saldivar en la exposición de motivos de la Ley Orgánica Municipal no 222/54, en donde se expresa que "en Paraguay, al igual que en toda Hispanoamérica, los Cabildos Coloniales, antecesores del municipio de hoy, tuvieron decisiva participación en la independencia y en la formación de las nuevas y jóvenes naciones". "El Cabildo de la colonia y posteriormente el de la independencia, constituyó el centro del gobierno de la comunidad y la sede del poder político y fue la primera y más 
auténtica expresión del constante anhelo de los pueblos de gobernarse por si mismos".

No podemos olvidar en la historia municipalista de Paraguay al que fue Alcalde del Primer Voto en el año 1808 "en el muy llustre Cabildo, justicia y Regimiento de la Ciudad de Asunción", Dr. José Gaspar de Francia, que no sólo fue el principal defensor del principio de autonomía de la Administración Local en el Cabildo de Asunción, sino que fue el director y consolidador de la Independencia Paraguaya y defensor incorruptible de dicha Nación.

EI Paraguay tiene, pues, desde su origen en los tiempos de la coIonia, tradición municipalista y un buen orientado sentido hacia la organización comunal como medio de gobierno para procurar el bienestar de los vecinos de ciudades, villas y pueblos.

La vigente Ley no 1294, Orgánica Municipal (predecesora de la Ley de 1881, renovada en 1909, que a su vez fue modificada en el año 1927 - año en el que se atribuyó a las leyes una numeración que fue la 915- prolongándose la vigencia de dicha Ley hasta el año 1954 en que se promulga la Ley Orgánica Municipal no 222), tendrá que ser inevitablemente modificada o sustituida por un nuevo texto legal que recoja las exigencias de los principios democráticos en el Paraguay.

El criterio prevalente de constitucionalistas paraguayos y de corrientes políticas de aquel país es que la designación del Intendente por el Poder Ejecutivo, atenta contra el principio de la autonomía municipal reconocido y recogido en el artículo 17 de la Constitución nacional, con un especial y deliberado énfasis. También consideran excesivo el intervencionismo de dicho Poder en los supuestos autorizados por el artículo 23 de la Constitución.

El artículo 58 de la Ley Municipal vigente, establece que "la Administración General de la Municipalidad sea ejercitada por un Intendente nombrado por el poder Ejecutivo, por un período de cinco años, pudiendo ser nuevamente designado". Es factible que la nueva reforma local atribuya la elección del Intendente Municipal por participación directa y sufragio de los vecinos del Municipio de que se tratara, lo que contribuiría a dar efectividad y vigor a los principios democráticos y a la autonomía municipal, que no debe confundirse con la soberanía, tal y como pone de relieve el Acuerdo y Sentencia de la Corte Suprema de Justicia Paraguaya de 10 de agosto de 1988 que establece que "la Autonomía municipal en nuestro derecho constitucional es relativa, dado que no se da a sí misma su carta orgánica, la que debe ser dictada por el Congreso y promulgada por el Poder Ejecutivo".

Son varios los puntos problemáticos que se deberán de resolver en las próximas modificaciones legales locales, aparte de las enunciadas; 
así, deberá de dilucidarse el papel del Estado con respecto a los Municipios en cuanto a las subvenciones a otorgar a los mismos para el cumplimiento de sus funciones, cuestión que nunca se ha planteado en Paraguay y que aparece recogida en textos locales europeos y latinoamericanos; las posibles transferencias del estado a los Municipios; la financiación de las municipalidades y la consolidación de las bases económicas del poder local; el establecimiento de las premisas básicas para la instauración de un Fondo de cooperación intermunicipal que constituye un auténtico reto para el desarrollo municipal paraguayo; la institucionalización de movimientos participativos vecinales, etc., etc.

Por otra parte, sugerimos, y en este sentido se pronuncia el municipalista paraguayo Dr. Chase Plate, que debería de estudiase la posibilidad del rescate de una antigua tradición española y americana sustituyendo la denominación actual de "Intendente" por la de "Alcalde". El citado autor considera que la denominación actual se adopta en unas circunstancias históricas determinadas en donde primaban las corrientes independentistas en la revolución del Río de la Plata, cuando primaba una corriente antiespañolista, hoy ampliamente superada por la gran amistad, colaboración y cooperación existente entre ambos países, España y Paraguay. En esta línea y dentro de la vertiente municipalista se encuadra la realización del I Encuentro Hispano-Paraguayo de Municipios, en la Ciudad de Asunción, durante los días 2, 3 y 4 de Mayo de 1990.

El momento municipal paraguayo, con la próxima celebración de elecciones en 1991 y la redacción de un nuevo texto legal municipal, asi como la preparación de todas las actividades necesarias para la elaboración del nuevo texto local paraguayo, y las reformas precisas y pertinentes al respecto de la Constitución de 1967, supone un esfuerzo y un trabajo importante para los diputados y miembros de la Comisión Municipal del Parlamento Paraguayo.

El recopilar documentación y trabajos cooperativos de la regulación del hecho "municipal" en América Latina o Europa como elemento esencial e imprescindible para poder sopesar y propiciar el estudio parlamentario de la temática local que coadyuve a la elaboración de un nuevo texto local o la reforma del existente con elementos de juicio suficientes, es una labor ardua al mismo tiempo que gratificante por el contenido, la esencia y la importancia de aquello que constituye el objeto de la regulación como es el devenir legislativo futuro del Municipio Paraguayo que hunde sus raices en el cimiento mismo del origen de la Nación Paraguaya. 


\section{II.- COOPERACION INTERMUNICIPAL ENTRE LOS PAISES HISPANICOS.}

El estudio de las normativas iberoamericanas sobre el aspecto Municipal no es reciente, como tampoco lo es la cooperación intermunicipal ibero-americana que se ha venido realizando ya en la segunda mitad de nuestro siglo, desde que se llevara a efecto, en 1955 y en Madrid, Granada y Sevilla el I Congreso Iberoamericano de Municipios. Con anterioridad y dentro del presente siglo, América ha expresado su común conciencia municipalista por medio de sus Uniones, y a partir de 1939 se constituye la Asociación Interamericana de Cooperación Intermunicipal, que celebraba Congresos bienales y publicaba un "Boletín" en el que traducía sus esfuerzos. Se aspiraba por aquel entonces a la formación de un Código Municipal Interamericano.

Por principios del siglo, Europa conoce instituciones como la UNION INTERNATIONAL DES VILLES ET POUVOIRS LOCAUX, fundada en Gante en 1913. Con posterioridad, y en la mitad del siglo actual, surgía la organización denominada ETATS GENERAUX DES COMMUNES D'EUROPE, que apelaba a las Administraciones locales del Continente Europeo y que celebró sus reuniones en diversas ciudades europeas. En Octubre de 1956, se reunian en Venecia mil cuatrocientas localidades que representaban a colectividades que agrupaban a varias decenas de millones de ciudadanos europeos para discutir problemáticas comunes al quehacer municipal, concluyendo todo el proceso intermunicipal europeo con la creación del Consejo de municipios y Regiones de Europa (C. M. R.E.).

Posteriormente, y en el ámbito municipal iberoamericano, se constituye la O. I. C. I. (Organización Interamericana de Cooperación Internacional) que ha organizado diversos congresos y reuniones, cuyas crónicas y ponencias fueron recopiladas por el entonces Instituto de Estudios de Administración Local. También hemos de recordar los congresos Hispano-Ruso-Americano-Filipinos de Municipios que han llevado a efecto diversas ediciones.

La I. U. L. A. (Unión Internacional de Autoridades Locales) tampoco ha sido ajena al proceso municipal iberoamericano, creando una sección Latinoamericana, cuya función es la del estudio de la realidad municipal en aquel continente y, últimamente, su Centro de Capacitación y Desarrollo de los Gobiernos Locales, ha organizado en Cartagena de Indias (Colombia) un seminario-taller bajo la rúbrica: "Recursos públicos y privados para financiar el desarrollo urbano en ciudades intermedias de América Latina y el Caribe". 
Organismos de creación más reciente, como la U. C. C. I. (Unión de Ciudades Capitales Iberoamericanas), contribuyen a mantener las relaciones entre las mismas a diversos niveles, y que partiendo del reconocimiento de origen comunes y de influencias recíprocas, se concretiza en una organización asociativa intermunicipal iberoamericana que abarcando todos los aspectos de la vida municipal realiza, asimismo, un intercambio beneficioso entre el personal técnico y administrativo de los Municipios asociados.

Desde la obra de Ruy de Lugo-Viña, como creador y heraldo de la Intermunicipalidad Universal, a la que consagró los mejores años de su vida y cuya labor fue reconocida por el Primer Congreso Iberoamericano de Municipios, han sido algunos $-y$ no muchos - los tratadistas modernos que han estudiado la interrelación intermunicipal comparada. Entre algunos de estos:

El gran autor municipalista FERNANDO ALBI, en su libro "Derecho Municipal Comparado del Mundo Hispánico", editado en 1955, sentó las pautas de investigación y comparación de las leyes municipales iberoamericanas y como ponía de relieve en la página 7 del citado trabajo:

"El mundo hispánico no es ni aspira a ser una unidad política ni económica, pero constituye una unidad espiritual".

El sentido de cooperación intermunicipal puede manifestarse en los municipios con un alcance que, precisamente por ser municipal, no comporta aspiraciones políticas ni roza los problemas de soberanía. De aquí el interés que ofrece una alianza iberoamericana de Municipios, o si se prefiere, de Corporaciones Municipales o de Municipalidades, términos que designan la representación legal de aquellos.

En España como en América, ha sido el Municipio relicario de libertades, entendiéndose así la similitud de estructuras. Si bien es cierto que en cada pais el Municipio ha adquirido consonancias proyectadas a la significación política de cada Estado, el origen común de la institución municipal en los países de habla hispana -a través de la figura del Cabildo castellano- ha impregnado todo el proceso evolutivo de aquellas municipalidades.

El Cabildo castellano del siglo XVI fue introducido en América para la organización de las ciudades y base de su edificio nacional, pero no para ser implantado con fiel exactitud al que regía en la Castilla de la época, sino con el criterio de adecuación y semejanza. Según el plan del Cardenal Cisneros, se deberían de "fundar pueblos de indígenas de hasta 300 vecinos. con iglesia, hospital y cacique cuya autoridad se conservaba". 


\section{III.- EL MUNICIPALISMO PARAGUAYO Y ESPAÑOL. HISTORIA COMUN.}

Como expusimos con anterioridad, el municipalismo nace en América Latina de la implantación de los cabildos castellanos en el siglo XVI, con todos los cargos y demás funcionarios aparejados a la institución.

La evolución del Cabildo Castellano hasta aquella fecha es ciertamente importante para entender el estado en que es ubicado en las tierras que iban siendo conquistadas por los españoles.

La institución jurídica del Cabildo que se instaura en Paraguay, tiene sus antecedentes en todo un trasiego histórico que constituye, en parte, la historia del Municipio español en la fase de la época que la doctrina ha llamado "Etapa preconstitucional" y que de alguna forma manifiesta los orígenes lejanos y remotos de la institución municipal paraguaya, pues mal se entendería la organización de la ciudad de Asunción en 1541 y la instauración del primer cabildo Paraguayo con toda su parafernalia, si no estudiáramos el origen de dicha institución en Europa, que fue transplantada a América y singularmente al Paraguay con toda la carga positiva que en su dinámica histórica fue generado para la independencia nacional paraguaya dicha institución.

Los antecedentes del Cabildo Castellano encuentran su justificación y su razón de ser en las siguientes etapas que moldean su configuración.

\section{A. Breve historia del municipio en España. Etapa preconstitu- cional}

En dicha cabe distinguir, al propio tiempo, las siguiente etapas:

- Prerromana.

- Dominación romana.

- Medievo.

- Monarquía absolutista.

\section{Etapa prerromana.}

No puede hablarse, en realidad, de la existencia del Municipio en el sentido que actualmente se utiliza este término. Existe, por el contrario, una nebulosa y cierto confusionismo entre Municipios y Estado soberano primitivo, bajo las fórmulas de Estados gentilicio y tribal. Incluso las primitivas colonias fenicias, griegas y cartaginenses 
eran algo más que simples Municipios, al poseer poderes soberanos, sin perjuicio de las relaciones de confederaciones entre ellas.

\section{Dominación romana.}

Inicialmente existe una graduación de las ciudades desde el punto de vista de la organización político-administrativa, según la menor o mayor dificultad de sometimiento a Roma, aunque estas diferencias fueron desapareciendo a medida que se produce el fenómeno de la "romanización" de la Península.

Esta graduación se produce dando lugar a la siguiente tipología de ciudades y comunidades:

* Colonias romanas: creadas por Roma y habitadas por ciudadanos romanos o latinos. Su organización es una prolongación de la existente en la metrópolis.

* Municipios: constituidos por antiguas comunidades indígenas que habían aceptado la romanización. Dentro de ellos aparecen dos clases, según que a sus habitantes Roma les hubiese concedido la soberania romana o simplemente la ius latii.

* Las ciudades y comunidades que no entraban en los grupos anteriores, eran núcleos indígenas que conservaron durante muchos años su carácter propio. A su vez, se subdividian en inmunes, federadas $y$ estipendiarias. Las inmunes tienen derecho propio y no contribuyen con impuestos a los romanos; las federadas habian pactado con los conquistadores; $y$ las estipendiarias eran las vencidas, a las que se les privó de su organización primitiva, estando sometidas al poder de los gobernadores y debiendo contribuir con impuestos a favor de Roma.

Las colonias y los municipios tienen una organización análoga, calcada de la existente en la metrópolis.

- Una asamblea o curia, de un centenar de personas, los decuriones.

- Dicha asamblea nombraba, entre sus miembros, a dos de ellos en las colonias (duumviri) y a cuatro en los municipios (quadrunviri), con funciones de jefatura.

- Se completa el cuadro con los ediles, encargados de los diversos servicios, y los cuestores encargados de las finanzas.

- Por último, la figura del defensor civitatis, magistrado encargado de defender a los particulares frente a las demasias de la curia. 


\section{Medievo.}

La organización municipal en la Edad media se corresponde con la feudal del Estado, estructurado en una serie de poderes jerarquizados entre sí, aún cuando la subordinación jerárquica fuera en muchos casos más nominal que efectiva. Por otra parte, el sistema feudal hace nacer el poder de la propiedad privada.

El hecho de la reconquista es básico en España para el nacimiento y pujanza del Municipio, a través de la "repoblación" de las zonas conquistadas a los musulmanes así como de las fronterizas de los territorios de éstos y de los reinos cristianos.

A fin de atraer pobladores a estas zonas peligrosas, los monarcas concedian a aquéllos una serie de privilegios recogidos en los Fueros municipales, concediéndoseles el derecho a tener su propio gobierno municipal, elegir sus gobernantes y acordar el establecimiento de sus impuestos.

\section{Monarquía absolutista.}

Al aparecer ésta, absorbiendo los múltiples poderes antes dispersos en el clero, en la nobleza y en las Ordenes Militares, el Municipio pierde su anterior autarquía, especialmente a través de la figura del Corregidor o Alcalde Mayor nombrado por la Corona, y a través también de la imposición estatal y del control de las finanzas municipales por parte de autoridades del Estado. Desaparece el sentido democrático o se atenúa, pero, en cambio, cobra mayor rigor la eficacia de los servicios, hasta el extremo de que, desde el punto de vista de la Administración municipal, puede considerarse esta época como aquélla en la que las competencias municipales, en el terreno de la eficacia, alcanzan su mayor brillantez y esplendor.

Sobre los dos principios expuestos (democracia municipal y eficiencia de la actividad de la Entidad Local) va a edificarse el régimen local español, y conseguir el equilibrio entre ambos es la tarea que ha preocupado al legislador de cualquier pais $y$, naturalmente, aunque ello no se expresara abiertamente, a las Leyes y proyectos españoles del último y del presente siglo.

\section{B. Origen jurídico inmediato que configura la organización del Primer Cabildo Paraguayo. Las Ordenanzas de Calos V de 1523.}

El origen jurídico inmediato que configura la organización y delimitación del Primer Cabildo Paraguayo, allá cuando, en el año 1541, un 
16 de septiembre, el fuerte fundado por Juan de Salazar se transforma en Ciudad por la acción de Domingo Martínez de Irala y sus Oficiales Reales, fue la Ordenanza de Carlos $V$ del año 1523, que constituían un verdadero tratado de urbanismo de la época y en las que se disponia:

"que las ciudades fundadas procuren tener cercana el agua para la conducción fácil al pueblo y heredades, y cercanos también los materiales necesarios para edificar, lo mismo que las tierras para cultivo y pastos;

"que no se elijan para ciudades sitios demasiado elevados, por la molestia del viento y la dificultad de los servicios, ni demasiado bajos sujetos a menudo a las enfermedades, sino sitios a mediana altura, no sujetos a niebla, batidos por los vientos del Norte y Mediodia, y cuando se edifique a la rivera de un río, que se disponga la ciudad de tal forma que, cuando salga el sol, dé primero en el pueblo que en el agua;

"que el terreno y cercanias que se han de poblar sean fértiles, abundantes de pasto, leña, madera, metales, agua dulce, gente natural, fáciles para la entrada y salida, y que no tenga cercanos lugares ni pantanos en donde se crien animales venenosos ni den margen a aguas corrompidas $y$ aires malsanos;

"que se funden las ciudades cercanas a rios navegables, para que tengan mejor trajín y comercio con los marítimos;

"que los solares para carnicerias, pescaderias, tenerias y otras oficinas que causen inmundicias y mal olor, se procuren poner hacia el río o el mar, a fin de que las poblaciones se conserven limpias y sanas;

"que se fabriquen los templos exentos y en alturas para que sean de todas partes vistos y venerados, y entre la plaza mayor y el templo se edifiquen las Casas Reales, el Cabildo, Consejo, Aduana y Atarazana;

"que en los lugares frios, las calles sean anchas, y angostas en los calientes, y donde hubiere caballos, que se las ensanche convenientemente, procurando no afear lo reedificado ni perjudicar a su defensa y comodidad;

"que se lleve siempre hecha la planta de la ciudad que se ha de fundar, y que sus solares se repartan por suerte entre sus moradores; "que se señale ejido competente para el pueblo en donde pueda recrearse, y dehesa para pastar caballos y ganados, y que se repartan tierras de la labor, segregándose el Consejo una buena cantidad de ellas para propios, y si hubieren tierras de regadio, se sorteen igualmente los lotes que de ellas se hicieren, dejando una parte baldia para los futuros pobladores; 
"que después de hechas las sementeras y acomodado el ganada, se comience con cuidado y diligencia a edificar las casa con buenos cimientos y paredes, para lo cual vayan los pobladores bien apercibidos de tablas, herramientas e instrumentos para edificar en brevedad y poca costa;

"que hecha la traza de la ciudad y repartidos sus solares, armen los pobladores, por pronta providencia, sus toldos o ramadas para guarecerse del tiempo;

"que los solares, edificios y casas sean de una forma, por requerirlo asi el ornamento de la población, y con amplios patios $y$ corrales para caballos, y bestias de servicio, a fin de que reinen la salud y la limpieza;

"que, fundada la ciudad, los pobladores elijan, entre los más hábiles y mejores, Justicia y Regimiento, y que cada cual registre el caudal que tiene para emplearlo en la nueva población; "que si por caso fortuito los pobladores no hubieren acabado de poblar dentro del plazo concedido, se les prorrogue prudencialmente el término, para que no pierdan lo gastado ni lo edificado".

Irala y los Oficiales Reales, y basados en los principios de la Ordenanza anteriormente citada, resolvieron:

"de aqui en adelante ... hayan y residan en el dicho pueblo cinco regidores, los cuales se junten en el Cabildo con la Justicia, en los días que por ellos fuere acordado, para que entiendan en todas las cosas concernientes a la buena gobernación de esta Ciudad de la Asunción, las cuales hayan y puedan hacer las Ordenanzas Municipales".

De este modo y aquel día, quedó asentada la ciudad de Nuestra Señora de Asunción. Los conquistadores - anota Cardozo-se habian convertido en ciudadanos. La creación militar de Salazar se convertia en una población civil con todos sus fueros y derechos, y el Paraguay dejó de ser "conquista" para ser considerada "Provincia" o "Reino".

Historiadores paraguayos señalan las bonanzas del Cabildo en cuanto institución ebria del afán de independencia nacional en contra de la Colonia. Los Cabildos Castellanos, al ser trasplantados a las Indias, rebotaron con fuerza y readquirieron su perdido vigor. Por ejemplo, el Cabildo de Asunción hizo oir su voz en cuestiones que interesaban a todo el Paraguay.

Integraban el Ayuntamiento dos o más Alcaldes (de primer y segundo voto), los Regidores, el Alguacil Mayor y el fiel Ejecutor. El Cabildo de Asunción lo componian: 
- Dos alcaldes de primer voto,

- Dos de segundo voto,

- El síndico procurador,

- El alférez real,

- El fiel ejecutory

- Ocho regidores.

Corresponde en Asunción a los alcaldes ordinarios el ejercicio en primera instancia de la jurisdicción ordinaria tanto en lo civil como en lo criminal, llevando una vara como símbolo de su autoridad.

El alférez real tenía un cargo de honor pues en las fiestas y manifestaciones era portador del estandarte real. El fiel ejecutor o almotacén era el encargado del reconocimiento de las pesas y medidas. Los regidores debian de regir, es decir, debían de administrar la Ciudad: sus breas, urbanismo, atender la salud pública, defender las perrogativas comunales, etc...

También era factible la existencia de Cabildos abiertos, que congregaban a los vecinos, estantes y habitantes de la ciudad para asuntos trascendentales. Esta forma de constituirse los Cabildos -que hoy serían los Concejos abiertos en España - fueron sin duda la máxima expresión democrática del municipio. Todos los vecinos del $\mathrm{Ca}$ bildo podian hablar, acudir y votar. Sin duda alguna, el más importante de los reunidos en Asunción fue el constituido el 24 de junio de 1723 , en la época de los comuneros, que adoptó resistir al Gobernador García Ros y sostener en el mando a Antequera.

En esta época de la historia paraguaya, junto al Cabildo de Asunción destaca el de Villarica.

El historiador paraguayo Julio César Chaves, en su "Compendio de Historia Paraguaya", opina que el Cabildo está unido estrechamente a la ciudad, pero muchos de ellos, por su importancia, jugaron un rol en asuntos de carácter virreinal o provincial. Por ejemplo, el Cabildo de Asunción hizo oir su voz en cuestiones que interesaban a todo el Paraguay.

Asimismo, Chaves estipula que se suele tener a los Cabildos como representantes del espíritu democrático, pero esta opinión es muy discutible. Los Cabildos no representaban al pueblo sino a una pequeña oligarquía, a los vecinos que eran sólo los encomenderos. Los estantes, los habitantes, y las otras clases sociales (indios, negros, mestizos), no tenían parte en la elección de Ayuntamiento.

Los miembros del Cabildo eran elegidos por primera vez por el Virrey o Gobernador. A veces el Rey otorgaba alguno de esos cargos en forma vitalicia. Los Cabildos sucesivos eran elegidos por el cesante el cual se reunía el 31 de diciembre. Este sistema dio lugar a serios 
abusos pues se abusaba de la reelección y del remplazo de parientes por parientes.

Los países hispanoamericanos han avanzado mucho por la vía del reconocimiento de la personalidad municipal. Este principio constituye una mística inspiradora de un estado de conciencia difundido por todo el Continente.

Muchos escritores americanos posteriores a la independencia han reconocido el carácter representativo de los Cabildos, cuya arquitectura era tan sólida que fueron destruidos instituciones como las del Virreinato y las Audiencias, quedaba el Ayuntamiento perdurando a través de las vicisitudes del proceso emancipador (así, el argentino Villegas Basavil, en el prólogo a la obra "Bajo la Campana del Cabildo", de José María Sáez Valiente, Buenos Aires, 1952).

\section{IV.- ALGUNAS CONSIDERACIONES PARA PROPICIAR UN PROYECTO DE COOPERACION MUNICIPAL CON LA REPUBLICA DE PARAGUAY.}

A) La reafirmación y consolidación de los vinculos históricos y culturales de ambos paises.

B) El fortalecimiento de una relación que han de afirmarse aún más en la perspectiva de 1992, fecha de gran significado para los dos países y para la Comunidad Iberoamericana de Naciones, en el marco del V Centenario del Descubrimiento, como oportunidad histórica para la reflexión y proyección de futuro de una Comunidad Iberoamericana de Naciones.

C) El compromiso de defender y hacer respetar los Derechos Humanos en el marco del Estado de Derecho, que es la garantía de la dignidad y seguridad de los ciudadanos.

D) La constatación de que España, especialmente a raíz de su adhesión a las Comunidades Europeas, y Paraguay, en el ámbito de su campo de acción, contribuirán a una intensificación de las relaciones de Europa con Iberoamérica.

E) La posibilidad del logro de una integración jurídica municipal dentro de la política de integración de América Latina.

F) La posibilidad, a través de convenios municipales iberoamericanos multilaterales, de sembrar las semillas que supondrían el nacimiento de un Derecho Internacional Intermunicipal Iberoamericano de inspiración en principios homogéneos comunes.

G) El acercamiento de posiciones en orden a la posibilidad del estudio conjunto de una CARTA DE VECINDAD IBEROAMERICANA con arreglo a la cual los vecinos de las ciudades españolas y paraguayas 
tengan iguales DERECHOS URBANOS que nos ayuden a organizar las fuerzas positivas, que hacen que la historia siga el camino que ha de llevarla, no al desastre, sino a la paz que continúa.

H) La posibilidad de proyectar la experiencia democrática municipal española, consagrada en un decenio de Ayuntamientos Democráticos, a la situación municipal paraguaya actual de consolidación del proceso democrático a nivel estatal y en los inicios de reformas sustanciales legislativas de inspiración representativa en la faceta municipal.

I) El compromiso de estudiar las instituciones jurídicas municipales para el logro de aquellas que, siendo más idóneas y depuradas bajo una técnica jurídica escrupulosa, consigan el que la prestación de los servicios municipales - de capital y sustancial importancia para los ciudadanos se proyecten y estén encaminados hacia el mejoramiento de las condiciones de vida.

J) El conocimiento por los legisladores paraguayos de las técnicas jurídicas municipales utilizadas en los países de la Comunidad Económica Europea a través de España, presente en aquella organización como miembro de pleno derecho y en Institutos Europeos Municipales. Información comunitaria municipal que servirá de elemento de valoración para la adopción de decisiones por el Cuerpo Legislativo Paraguayo en orden a la construcción de la arquitectura jurídica municipal patria.

K) Fortalecimiento de los lazos de unión entre instituciones municipales paraguayas (O. P. A. C. I.) y el Instituto de Desarrollo Municipal (I. D. M.) e instituciones iberoamericanas municipalistas (U. C. C. l.).

L) la cooperación contemplaría la posibilidad de intercambio de técnicos municipales o la realización de Cursos monográficos para la formación intensiva y acelerada de cuadros medios (administrativos y técnicos) en temas municipales.

\section{V.- ALGUNAS CONSIDERACIONES EN TORNO \\ A LA AUTONOMIA MUNICIPAL. SIGNIFICADO DE LA AUTONOMIA MUNICIPAL EN IBEROAMERICA.}

Siguiendo al que fuera experto de Naciones Unidas, Sr. Larrainzar Yoldi, en las naciones que componen el hemisferio denominado iberoamericano imperan los principios tradicionales del municipalismo, descansando su base actual, de modo exclusivo, en las teorias jus-naturalistas de TOCQUEVILLE, POSADAS y los norteamericanos de principios de siglo. En este aspecto, el profesor VILLALBA MAFFIODO 
(profesor de Derecho Administrativo en la Universidad Nacional y en la Católica de Nuestra Señora de la Asunción) pone de relieve en su obra "Principios de Derecho Administrativo" que "EI DERECHO MUNICIPAL QUE SE APOYE Y RESPONDA CUMPLIDAMENTE A LAS CONDICIONES NATURALES DEL MUNICIPIO, PUEDE SER CONSIDERADO FUNDAMENTALMENTE COMO DERECHO NATURAL MUNICIPAL".

El entender que el Derecho Municipal es la Piedra angular de todo el Derecho Público; el considerar que el Municipio, tal como lo hizo el brasileño PENA CHAVES, es un "verdadero micro-Estado Nacional"; el calificar como premisas básicas de la autonomía que los Municipios ostenten la facultad de darse su propia forma de gobierno, de elegir sus propios gobernantes, determinando sus propias necesidades, de establecer sus servicios y aprobar sus sistemas tributarios en uso de la potestad legislativa y del poder fiscal originario, fueron los fundamentos para las declaraciones autonómicas que se hicieron en el primer Congreso panamericano de Municipios, celebrado en La Habana en 1938; en el segundo Congreso interamericano de Municipios, que tuvo lugar en Chile en 1941; en el tercer Congreso que se celebró en Nueva Orleans en 1950, en el que se planteó la aspiración de "Municipios autónomos dotados de amplios poderes de determinación en asuntos políticos, administrativos y fiscales" y, sobre todo; en el cuarto Congreso reunido en Montevideo en 1953, en cuyos documentos se afirma, en la Resolución Primera, lo siguiente:

"La autonomía municipal se caracteriza por el reconocimiento en la Constitución:

1‥ De la autonomía política, fundada en los principios democráticos.

$2^{\circ}$. De la capacidad financiera, con recursos adecuados para el cumplimiento de sus fines.

3o. De la administración propia de los servicios públicos locales".

En la actualidad, la autonomía municipal en la Ley vigente $\mathrm{n}^{\circ}$ 1294/87 de la República de Paraguay, viene recogida en el artículo 11, en donde se determina que "las Municipalidades Paraguayas son autónomas en el orden político, jurídico, económico y administrativo. Dicha autonomía sera ejercitada en los términos consagrados por la Constitución Nacional y en esta Ley". En armonía con la Constitución Nacional paraguaya vigente, sancionada y promulgada el 25 de agosto de 1967, dedica los artículos 17 a 23 a establecer la autonomía 
municipal. Corresponde, en esencia, al municipio, la elección y designación de sus autoridades, la libre gestión en la materia de su competencia, la determinación de sus bienes y los requisitos y limitaciones para disponer de ellos, así como la de sus ingresos y la forma de recaudarlos e invertirlos, la responsabilidad del gobierno municipal, y los recursos contra sus resoluciones.

Con la reforma que se prevé, el contenido de la autonomía en alguna de sus facetas deberán de ser colmadas de contenidos cual es la relativa a la elección y designación democrática de las autoridades. En este sentido, en la actualidad se ha criticado por fuerzas políticas y sociales algunos aspectos de la Ley 1294/87 en cuanto se determina la elección del Intendente por el Presidente de la República.

\section{A) Contenido esencial de la autonomía municipal.}

A continuación, transcribimos, a efectos orientativos, las Conclusiones Definitivas del Congreso Iberoamericano de Profesores de Derecho Administrativo en torno al contenido de la Autonomía Local:

"Primera. Se considera que es fundamental el reconocimiento de la municipalidad como entidad político-administrativa, cuyos órganos de gobierno tienen que ser necesariamente elegidos por el pueblo.

Segunda. Se entiende que el reconocimiento constitucional del principio de la autonomía municipal tiene que ir acompañado de la formulación de las líneas generales de su contenido, asi como también del establecimiento de su garantía.

Tercera. Se estima que es esencial que la distribución de las competencias municipales se efectúe por ley orgánica o básica. En este sentido se incluye dentro de las mismas, como mínimo, las siguientes:

- Urbanismo.

- Abastos.

- Educación y cultura.

- Salubridad.

- Asistencia social.

- Policía municipal.

- Infraestructura y servicios municipales.

- Alumbrado público.

- Defensa civil y emergencia.

- Abastecimiento de agua y saneamiento.

- Medio ambiente.

- Transporte urbano. 
- Ornato local.

- Tránsito local.

- Conservación y administración de los bienes municipales.

Cuarta. se considera que es ineludible la asignación legal de los recursos precisos para hacer efectiva la autonomía local, asi como también con el ejercicio de las competencias atribuidas.

Quinta. Se entiende que la autonomía municipal exige la potestad normativa.

Sexta. Se considera que igualmente es necesario el reconocimiento de la potestad administrativa para acordar su régimen de organización y funcionamiento, incluso para estructurar entidades supramunicipales sobre la base del concierto de esta potestad de los municipios afectados.

Séptima. Se considera, asimismo, esencial el reconocimiento de la potestad tributaria, financiera y patrimonial.

Octava. Se considera que son compatibles con la autonomía local los controles de legalidad.

Novena. Se entiende que el asesoramiento y la asistencia técnica prestada por Entidades públicas especializadas, a petición expresa de las municipalidades, tampoco es incompatible con la autonomia local, sino que incluso contribuye a hacerla más efectiva al proporcionarles en cada caso, el apoyo adecuado.

\section{VI.- ESTUDIO COMPARATIVO DE LA EVOLUCION LEGISLATIVA LOCAL HISPANO-PARAGUAYA.}

\section{A. Evolución legislativa local paraguaya.}

Siguiendo al profesor VILLAGRA MAFFIODO, en la evolución legislativa local paraguaya se encuentra la siguiente normativa:

- Ley Orgánica Municipal de 1882.

El 7 de junio de 1882 se dicta la primera Ley Orgánica de Municipalidades en la Cíudad de Asunción y "en las villas y pueblos que a juicio del Poder Ejecutivo sean necesarios cuerpos municipales en la forma y con las atribuciones que prescribe la presente Ley". El Municipio de la Capital elegía dos miembros titulares y dos suplentes por cada uno de sus distritos Catedral y Recoleta, Encarnación y Larbaré, San Roque y Trinidad, y cuatro titulares y dos suplentes los demás pueblos y villas. No existía todavía la figura del Intendente, sino que 
eran Presidentes de las Juntas o Consejos Municipales. Es en 1891 cuando se crea el primer cargo de Intendente para la Municipalidad de la Capital, quedando a su cargo exclusivo las atribuciones "que sean de carácter administrativo o que se relacionen con la ejecución de las disposiciones dictadas por la Corporación.

- Ley 915, de 1 de septiembre de 1927.

Organiza las Municipalidades en todo el país, confiriéndolas gobierno propio y cierta autonomía. En opinión del profesor VILLAGRA MAFFIODO, sus fuentes pueden encontrarse en las leyes municipales argentinas y a través de estas en las norteamericanas en lo relativo a la autonomía y a la distribución de competencias entre los órganos del gobierno municipal.

- Ley 222, antecesora de la actual.

La Ley 222 tiene por objeto la "revisión, ordenamiento y modernización" de la Ley 915. Sus fuentes son - siempre siguiendo al profesor VILLAGRA MAFFIODO-:

- La Ley 915, antes enunciada.

- Los principios proclamados en los Congresos Panamericanos de Municipio.

- Las resoluciones del Congreso de Municipalidades que se realizaron en Paraguay en 1952, y

- La Ley Municipal de Ecuador.

Hay que hacer constar, en línea con el profesor VILLAGRA, la influencia argentina en la legislación municipal paraguaya; lógica debido a la proximidad geográfica y a la evolución histórica común, lo que ha contribuído asimismo al logro de una misma evolución jurídica.

La influencia argentina se proyecta sobre los legisladores municipalistas de Uruguay, Bolivia y Chile, junto con Paraguay.

El profesor CHASE PLATE sugiere la transformación semántica que desemboca en Alcalde, término que se utiliza en el léxico jurídico local español y de varios países hispanoamericanos; concretamente en la última reforma local venezolana, se acuño el término "alcalde" en contraposición al término "Presidente del Consejo Municipal", que se venía utilizando en la anterior legislación. "Alcalde" deriva del término árabe kadi, cuya versión castellana parece haberse adoptado por mozárabes en forma de alkadi o el-kadi con significación de juez; variando sustantivamente las funciones del Alcalde a través de la historia. 
Haciendo un poco de historia en torno al término "Intendente", utilizado en Paraguay para llamar a las más alta jerarquía municipal, se puede decir que los Intendentes son una institución de origen francés, traída a España por Felipe $V$ en 1749, pasando a América por una Ordenanza de 1786, que constituía un extensísimo Cuerpo legal de 306 artículos. Como refiere PEREZ BUA, se hace de esos funcionarios una autoridad gigante, con una competencia realmente desmesurada.

HANOTAUX describe gráficamente dicho instrumento del absolutismo refiriéndose a esos "...agents ardents, vigoreux, ingénieux, se glissant, s'imposant ou bousculant las anciennes administrations pour se faire place, touchant à tout, au militaire, au civil, à la justice, aux finances, agents de commandement et agents d'exécution, ne dépendant que de la cour, et responsables seulement devant le roi".

Pero no debemos cometer el error de considerar al Intendente Municipal de la región del Plata, ni aún en sus primeros tiempos, como una supervivencia de viejo Intendente franco-español. Se trata de una simple coincidencia de nombre, y aún de una coincidencia meramente caprichosa. Al discutirse la Ley del Distrito Federal argentino en 1882, se buscaba una denominación para designar el órgano ejecutivo municipal que no fuera la española de Alcalde. "La Comisión necesitaba llamarlo de alguna manera para referirse a él y para expresar las facultades que a él se refieren, y lo ha llamado "Intendente Municipal", sin que tenga empeño de ninguna especie en sostener ese título, y está dispuesta a que la Cámara le dé el que mejor le parezca, si es que éste no le parece bien".

El entronque argentino de la legislación orgánica del Paraguay es patente y estrecho. Así, por ejemplo, la Ley 915 Orgánica Municipal de 1 de septiembre de 1927, mira también a Buenos Aires y se inspira plenamente en la Ley 1260 de aquel Distrito Federal, que constituye la base de más del 40 por 100 del texto paraguayo. Veamos un ejemplo cualquiera:

\section{PARAGUAY}

Art. 47. Son atribuciones del Intendente:

1‥ Dictar un Reglamento interno para las oficinas de su dependencia.

$2^{\circ}$. Promulgar las Ordenes de la Junta y darles cumplimiento.

3o. Vetar, en término de diez días hábiles, las Ordenanzas que estime ilegales o inconvenientes, inclusive el presupuesto de gastos y cálculo de recursos; pero si la Junta mantiene su resolución por dos tercios de votos sobre la totalidad de sus miembros deberá promulgarlas y cumplirlas. 
DISTRITO FEDERAL DE BUENOS AIRES

Art. 59. Son atribuciones y deberes del Intendente Municipal:

20. Dictar un Reglamento para el régimen interno de sus oficinas.

3 Promulgar las Ordenanzas sancionadas por el Consejo Deliberante, y proveer a su ejecución por medio de los empleados a sus órdenes dictando las disposiciones reglamentarias del caso.

4․ Observar, en término de cinco días útiles, las Ordenanzas que estime ilegales o inconvenientes, incluso las del presupuesto general...

La Ley paraguaya es de extensión similar a las argentinas -107 artículos; igual número en San Luis-. Su distribución es análoga a la del Distrito Federal y a las de varias provincias de dicha Repúblicas. Su contenido no discrepa del Distrito más que en la materia electoral, que en el Paraguay se omite en absoluto.

- Ley 1294/87, Orgánica Municipal.

Es la que actualmente se encuentra vigente. Si bien se anuncia su reforma en un futuro inmediato.

Como la anterior Ley 222/54 que contaba con 227 artículos, la Ley vigente en la actualidad está dividida en:

- Títulos,

- Capitulos y

- Secciones.

Sus once Títulos cuentan con 254 artículos. Fue promulgada el 18 de diciembre de 1987, entrando en vigor a los sesenta días de su promulgación (art. 253, segunda parte), derogando no sólo la Ley Orgánica anterior, sino todas las demás disposiciones contrarias, y así:

“TITULO PRIMERO DEL MUNICIPIO.

CAPITULO PRIMERO. SECCION PRIMERA. DEL MUNICIPIO EN GENERAL.

Se define el MUNICIPIO PARAGUAYO como la COMUNIDAD DE VECINOS CON GOBIERNO PROPIO, QUE TIENE OBJETO PROMOVER EL DESARROLLO DE LOS INTERESES LOCALES. CUYO TERRITORIO COINCIDE CON EL DEL DISTRITO Y SE DIVIDE EN ZONAS URBANAS, SUBURBANAS Y RURALES". 
La palabra 'municipio' proviene del latín 'municipium' que, en tiempos del dominio romano, significa 'ciudad que se gobierna por sus propias leyes'

El artículo 1 de la Ley Reguladora de las Bases del Régimen Local, define los municipios como "entidades básicas de la organización territorial del Estado y cauces inmediatos de participación ciudadana en los asuntos públicos, que institucionalizan y gestionan con autonomía los intereses propios de las correspondiente colectividades".

La definición municipal paraguaya describe los elementos integrantes del Municipio:

- Grupo de habitantes que viven avecinados.

- Gobierno propio; lo que hace referencia al elemento organizativo, esencial en toda organización administrativa, y

- Territorio, espacio físico cuyos límites jurisdiccionales coinciden con el distrito y asiento de la comunidad de vecinos.

La definición española se detiene a considerar al municipio como elemento integrante del Estado, como institución de la estructura descentralizada del Estado, reseñando la participación en el mismo de los vecinos en los asuntos públicos que les atañen y remarcando la existencia de la "autonomía" municipal consagrado en el texto constitucional.

La Sentencia del Tribunal Constitucional español, de 2 de febrero de 1981, delimita conceptualmente la autonomía local, estableciendo que "la Constitución Española parte de la unidad de la $\mathrm{Na}$ ción española, que se constituye en Estado social y democrático de Derecho, cuyos poderes emanan del pueblo español, en el que reside la soberania". "Esta unidad se traduce en una organización para todo el territorio nacional, pero los órganos generales del Estado no ejercen la totalidad del poder público, porque la Constitución prevé, de acuerdo con una distribución vertical de poderes, la participación en el ejercicio del poder de entidades territoriales de distinto rango".

Continúa la Sentencia poniendo de relieve que "Ia autonomía hace referencia a un poder limitado. Autonomía no es Soberanía, y dado que cada organización territorial, dotada de autonomía, es una parte de un todo, en ningún caso el principio de autonomía puede oponerse al de unidad, sino que es precisamente dentro de ésta donde alcanza su verdadero sentido".

La autonomía municipal española es de carácter administrativo y no de carácter político. 
El Acuerdo y Sentencia de la Corte Suprema de Justicia Paraguaya del 10 de agosto de 1988, recaída en la acción de inconstitucionalidad planteada por el Intendente Municipal de Asunción contra las Ordenanzas Número 24783, 24794, 24795 y 24884 del año 1988, determina, en lo concerniente a la autonomía municipal que, en el derecho constitucional paraguayo es relativa, dado que no se da a sí misma su carta orgánica, que debe ser dictada por Ley por el Congreso y promulgada por el Poder Ejecutivo. Continúa dicho Acuerdo en el sentido de que por ende, la Honorable Junta Municipal, al dictar Ordenanzas, debe de respetar la Ley de Organización de los Municipios y no puede modificarla o derogarla. Si algo está mal en dicha Ley 1294/87, debe proponerse su enmienda al Congreso Nacional, pero la Honorable Junta Municipal no tiene potestad jurídica ni constitucional para modificar una Ley; si lo hace, es un acto nulo por inconstitucional, y por tanto sin valor, siendo inaplicables sus disposiciones".

(Titulo I. Capitulo I.)

"Sección 2a. De la creación, fusión, supresión y anexión de los municipios.

Capítulo II. de la Municipalidad.

Capítulo III. de la Autonomía Municipal.

Capitulo IV. del Objeto y Función Municipal.

Capítulo V. de las Relaciones con el Poder Ejecutivo.

Título Segundo. Del Gobierno Municipal.

Capítulo I. Generalidades.

Capitulo II. de la Junta Municipal.

Sección 1ạ. de la elección, composición y proclamación.

Sección $2^{a}$. de la instalación y del funcionamiento.

Sección $3^{a}$. de las atribuciones y los deberes de la Junta Municipal.

Sección $4^{a}$. de la formación y sanción de las Ordenanzas, los reglamentos y resoluciones.

Capitulo III. de la intendencia municipal.

Sección 1a . de la designación, atribuciones y deberes del intendente municipal.

Sección $2^{\mathrm{a}}$. de la Secretaría.

Sección $3^{a}$. de la Policía municipal.

Sección $4^{a}$. de las Juntas comunales de vecinos.

Sección 5a. de las comisiones de Fomento Urbano. 
Capítulo IV. de los juzgados de faltas municipales.

Sección 1‥ de los juzgados de faltas municipales.

Sección $2^{2}$. de los recursos contra las resoluciones de los jueces de faltas municipales.

Título Tercero. De los bienes municipales.

Capítulo I. de la clasificación.

Capitulo II. de los bienes de dominio público.

Capítulo III. de

Título Cuarto. De los Ingresos Municipales.

Capítulo I. Generalidades.

Capítulo II. de los ingresos tributarios.

Sección 1a. de los impuestos.

Sección $2^{\mathrm{a}}$. de las tasas.

Sección $3^{\mathrm{a}}$. de las contribuciones especiales.

Capitulo III. de los ingresos no tributarios.

Capítulo IV. de los empresarios.

Capítulo V. de las multas.

Capítulo VI. del cobro de las deudas por vía judicial.

Titulo Quinto. De la Administración Financiera Municipal.

Capitulo I. Generalidades.

Capítulo II. del Presupuesto.

Sección 1a. de la elaboración del Presupuesto.

Sección $2^{2}$. de la sanción y promulgación del Presupuesto.

Capítulo III. de la ejecución del Presupuesto.

Titulo Sexto. del planteamiento físico y urbanístico.

Capítulo I. Generalidades.

Capítulo II. del planteamiento físico municipal.

Capítulo III. de la superficie y limite de las zonas urbanas.

Capitulo IV. del planteamiento del desarrollo urbano.

Capítulo V. de los loteamientos.

Capítulo VI. de los conjuntos habitacionales y de la propiedad horizontal.

Capitulo VII. del régimen de servidumbre.

Capítulo VIII. de la expropiación.

Capitulo IX. de los clubes de campo. 
Título Séptimo. del régimen de la contracción municipal.

Capítulo único de la contratación de obras y la adquisición de bienes.

Título Octavo. de la cooperación municipal e interinstitucional.

Capítulo I. de la organización paraguaya de cooperación intermunicipal. (O. P. A. C. I.).

Capítulo II. de las asociaciones de municipalidades.

Capítulo III. de las entidades de desarrollo municipal.

Capítulo IV. de la participación de las municipalidades en los ingresos fiscales.

Capítulo V. de la asistencia intermunicipal.

Capitulo VI. de la cooperación interinstitucional.

Título Noveno. de las acciones y recursos contra las resoluciones y demás actos municipales.

\section{B) Evolución legislativa local española.}

En lo relativo a la evolución legislativa de los textos legales municipales españoles a partir de la Constitución de 1812, podemos distinguir dos etapas:

- Centralista, en la que los municipios están sometidos a un sistema de recursos de alzada ante órganos del Estado, $y$

- Autonomica, a partir del Estatuto de 1924, en el que se instaura la descentralización.

\section{1.- Etapa Centralista.}

- Ley de 3 de febrero de 1823.

Regula los Municipios y sus órganos dentro de un marco netamente centralizador, ya que el sometimiento de aquéllos a la Diputación los jerarquiza considerándolos creaciones artificiales de la Ley, además del sentido paternalista propio de la época y carente de toda posible autonomía.

- Decreto de 23 de julio de 1835.

Reintegró a los Municipios en el goce de las atribuciones que les diera la Constitución de 1812. Al poco tiempo, y por Decreto de 15 de octubre de 1836, se puso de nuevo en observancia la Ley de 1823.

- Ley de 14 de julio de 1840. 
No entró en vigor hasta que por el Real Decreto de 30 de diciembre de 1843 pasó a sustituir a la Ley de 1823. Tenía la misma tendencia que el anterior Decreto de 1835.

- Ley 8 de enero de 1845.

Sigue la misma pauta de la Ley de 1823 en lo referente a la falta de autonomia de las entidades locales y a la estructura racionalista y artificial del Municipio con sometimiento total al control del Estado.

- Decreto-Ley de 21 de octubre de 1868.

Salvo pequeñas diferencias, puso en vigor una Ley votada por las Cortes Constituyentes en 1856, que no había llegado a regir porque un Real Decreto de 16 de octubre del mismo año que los Ayuntamientos se sujetasen a la Ley de 1845.

- Ley de 20 de agosto de 1870.

Fue elaborado por las Cortes Constituyentes de 1869 y tiene un sentido ecléctico entre las dos tendencias que vienen apareciendo a lo largo del siglo. Sufre algunos retoques en 1876.

- Ley de 2 de octubre de 1877.

Es un compendio de la Ley de 1870 y de los retoques introducidos en 1876. Al igual que aquélla, pretende armonizar las dos tendencias políticas imperantes, pero manteniendo el sentido centralizador, aunque con ciertas concesiones a ideas más abiertas en cuanto a la elección de órganos. Respecto al control de actos, denotaba el sentido de suspensiones y recursos ante la Diputación o Gobernador, según los casos.

\section{2.- Etapa Autonómica.}

- Estatuto Municipal de 8 de marzo de 1924.

Es el que verdaderamente concede la autonomía y aplica la descentralización a las Entidades municipales, manifestada en dos vertientes: electividad de los órganos y supresión de las alzadas, pasando a ser los órganos judiciales los competentes en la impugnación contra los acuerdos municipales.

- Ley Municipal de 1935.

Sigue la pauta del Estatuto, si bien se llegó a implantar la posibilidad de elección de Alcaldes por el pueblo, junto a la elección de los mismos por los Ayuntamientos.

- Ley de Régimen Local de 1945 y textos artículos de 1950 y 1955.

Han regulado conjuntamente los regímenes municipal y provincial por primera vez, y han constituido, con diversas modificaciones posteriores y junto con una profusa reglamentación, un estatuto legal de gran importancia y eficacia en nuestra historia legislativa, que supusieron una transformación sustantiva de nuestra vida local. 
- Ley 41/1975, de Bases del Estatuto de Régimen Local.

Sólo fue desarrollada en lo referente a las Haciendas Locales por el Real Decreto 3250/1976, y en lo referente a la función pública local y otros extremos, por el Real Decreto 3046/1977 de 7 de octubre.

\section{3.- Etapa actual.}

- Ya la Ley 40/1981, de 28 de octubre, introduce importantes innovaciones en el Régimen Local (régimen jurídico, función pública, régimen económico-financiero, etc.), pero la moderna reforma en profundidad está recogida en la Ley 7/1985, de 2 de abril, Reguladora de las Bases del Régimen Local, así como en el Texto refundido de las disposiciones legales vigentes en materia de Régimen Local, aprobado por Real Decreto legislativo 781/1986, de 18 de abril.

\section{VII.- DISPOSICIONES LEGISLATIVAS MUNICIPALES PARAGUAYAS EN VIGOR Y RELACIONADAS CON LA LEY № 1294, ORGANICA MUNICIPAL DE PARAGUAY.}

- Ley no 1294/84. "Orgánica Municipal".

- Ley $n^{\circ} 881 / 81$. Que establece el régimen tributario y de otros recursos para la Municipalidad de Asunción.

- Ley n은 620/76. Que establece el régimen tributario para las municipalidades de $1^{a}, 2^{a}$ y $3^{a}$ categorias.

- Ley $n^{\circ}$ 1053/83. de catastro de la ciudad de Asunción.

- Ley no 291/71. Que crea el Instituto de Desarrollo Municipal (I. D. M.).

- Estatutos sociales de la Organización Paraguaya de Cooperación Intermunicipal (O.P. A. C. I.).

- Estatutos sociales de la Asunción de Municipalidades del Area Metropolitana (A. M. U. A. M.).

- Ordenanza no 25098/89. Que aprueba el Plan Regulador para la ciudad de Asunción.

- Ordenanza no 16405/86. Que declara zona de interés público comunal a áreas libres mayores de $15.000 \mathrm{mts} 2$. sobre avenidas.

- Ordenanza no 22915/87. Que crea el Registro de proyectistas, calculistas y constructores y establece sus categorias, perrogativas, responsabilidades $y$ sanciones.

- Ordenanza no 22119/87. Que sectoraliza la ciudad de Asunción para uso del catastro.

- Ordenanza no 20240/86. Que reglamenta las normas y procedimientos del catastro municipal de Asunción. 
- Ordenanzas $n^{\circ} 5929 / 66$ y no $17387 / 85$. Que prohíben la fijación de anuncios y/o leyendas en la vía pública.

- Ordenanza no 18108/85. Sobre monumentos, monolitos, placas memorativas.

- Ordenanza no 12225/83. Que regula los proyectos de conjuntos habitacionales en Asunción.

- Ordenanza $n^{\circ}$ 10811/83. Sobre delimitación y designación de barrios de Asunción.

- Ordenanza $n^{\circ} 6057 / 82$. Que reglamenta las condiciones de seguridad en las edificaciones.

- Ordenanza no 6008/82. Que establece el procedimiento en los Juzgados de Faltas Municipales.

- Ordenanza $n^{\circ}$ 6339/82. Que establece sectores residenciales en la ciudad de Asunción.

- Ordenanza no 5556/81. Que establece sectores "eminentemente residenciales" en la ciudad de Asunción.

- Ordenanza $n^{\circ}$ 5486/81. Que establece la obligatoriedad de ductos para líneas telefónicas en las edificaciones.

- Ordenanza no 4462/80. Que aprueba el trazado de la autopista y circunvalatoria norte.

- Ordenanza $n^{\circ} 3722 / 80$. Que establece la obligatoriedad de pórticos en ciertas aceras de Asunción.

- Ordenanza $n^{\circ} 3553 / 79$. Que regula las construcciones frente a las plazas y parques.

- Ordenanza $n^{\circ} 1196 / 78$. Que reglamenta el tránsito de vehículos pesados en Asunción.

- Ordenanza no 1195/78. Que establece la obligación de conservar las fachadas de edificios en buen estado.

- Ordenanza no 9979/77. Que prohíbe la ocupación, venta o arrendamiento de terrenos en el Banco de San Miguel.

- Ordenanza no 9928/76. Que reprime la producción de ruidos molestos.

- Ordenanza no 8358/72. Que crea Oficina de Desarrollo Urbano de Asunción,

- Ordenanza no 7409/70. Que delimita zonas de renovación urbana y de interés público comunal de Asunción.

- Ordenanza no $6436 / 67$. Que aprueba un contrato tipo para arrendamiento de terrenos municipales.

- Ordenanza $n$ ㅇ 6431/67. Sobre adquisición de tierras municipales.

- Ordenanza no 1967/39 y 1978/50. Sobre loteamiento.

- Ordenanza $n^{\circ} 2777 / 53$. Que establece el régimen de remoción parcial del pavimento $y / 0$ veredas para obras.

- Reglamento de loteamiento para la ciudad de Asunción. 


\section{VIII.- LEGISLACION LOCAL VIGENTE EN ESPAÑA EN LA ACTUALIDAD.}

- Ley 7/85 de 2 de abril, Reguladora de las Bases de Régimen Local.

- Real Decreto 781/86, de 18 de abril; por el que se aprueba el Texto refundido de las disposiciones legales vigentes en materia de Régimen Local.

Consta dicho Texto refundido de 461 artículos, 9 disposiciones transitorias, 8 disposiciones finales, disposición derogatoria y disposición adicional.

Está dividido en 8 títulos que son:

1‥ Disposiciones generales.

2․ El Municipio.

3․ La Provincia.

4․ Otras Entidades Locales.

5‥ Disposiciones comunes a las Entidades Locales.

6‥ Bienes, Actividades, Servicios y Contratación.

7․ Personal al servicio de las Entidades Locales.

8.. Haciendas Locales.

- Ley 11/60, de 12 de mayo; por la que se regula y crea la Mutualidad Nacional de Previsión de la Administración Local relativa a la Seguridad Social de los funcionarios que prestan sus servicios en las Administraciones Locales españolas.

Asimismo, existen vigentes las siguientes disposiciones:

- Reglamento de Bienes de las Entidades Locales. (R.D. 1372/86, de 3 de julio).

- Reglamento de Población y Demarcación Territorial. (R.D. 1690/86, de 11 de julio).

- Reglamento de Organización, Funcionamiento y Régimen Jurídico de las Entidades Locales (R.D. 2568/86, de 28 de noviembre).

- En materia de personal, se ha dictado el Real Decreto 1174/87, de 18 de septiembre, por el que se regula el régimen jurídico de los funcionarios de Administración Local con habilitación de carácter nacional.

- En materia de Haciendas Locales hay que citar la Ley 39/88, de 28 de diciembre.

\section{IX.- ASPECTOS CONCRETOS EN LOS QUE SE DETERMINA LA COOPERACION ESPAÑOLA EN MATERIA MUNICIPAL.}

Siguiendo la definición que la Real Academia de la Lengua Española al término COOPERAR - "obrar juntamente con otro u otros para 
un mismo fin" - , y teniendo en cuenta el momento actual del municipalismo paraguayo y en armonía y coordinación con los Institutos municipalistas paraguayos (Instituto de Desarrollo Municipal, I.D.M.; Organización Paraguaya de Cooperación Intermunicipal,;(O.P.A.C.I.); Comisión de Asuntos Municipales de la Cámara de Diputados), organismos que debieran oirse en orden a adoptar alguna resolución al respecto, y considerando:

I. La andadura del nuevo Código Electoral que habilitará la celebración de Elecciones Directas de Intendentes.

II. Las Elecciones Directas de Intendentes, a celebrar en el primer semestre del año 1991.

III. La Reforma de la Ley no 1294/87, Orgánica Municipal.

IV. La puesta en marcha de nuevos mecanismos Institucionales de representación vecinal y ciudadanos.

V. Las necesidades de las Juntas Municipales paraguayas en el orden técnico para el cumplimiento de sus atribuciones y deberes.

VI. El desarrollo efectivo y democrático de las Juntas Municipales en el orden urbanístico y de la planificación física, en el orden higiénico, salubridad y servicio social, educación, deporte y turismo, recursos naturales y medio ambiente, seguridad y tránsito, espectáculos públicos, etc.

VII. La perfectibilidad del apoyo municipal a las entidades de desarrollo y cooperación.

VIII. El apoyo decidido y participación de los municipios al desarrollo económico de su Término Municipal.

IX. La configuración de un nuevo sistema de Financiamiento Municipal Paraguayo pasa por elaborar las premisas de consenso adecuadas con las entidades estatales fiscales y hacendisticas para la consecución de un modelo subvencionador Estado-Municipios que permita a éstos el cumplimiento de sus fines sociales.

$X$. El desarrollo turístico es un aspecto del desarrollo económico del país en el que los entes municipales paraguayos están llamados a proponer políticas puntuales de promoción.

XI. Que el Municipalismo Español cuenta con diez años de experiencia democrática y ha solventado muchos de los problemas anteriormente apuntados y en diversos órdenes.

XII. Que como continuación del 10. encuentro Hispano-Paraguayo de Municipios, en donde se ha dado un importante avance en la cooperación Municipal entre ambos países y en donde se ha dado un repaso de los momentos históricos en donde se encuentran 
ubicados el "Hecho Municipal" Paraguayo y Español, se deben de adoptar medidas de apoyo concreto del Municipalismo Español al Municipalismo Democrático Paraguayo a través de Organizaciones Cooperadoras Españolas.

A la vista de todo lo anteriormente expuesto, podriamos señalar las siguientes propuestas concretas.

1.- Primera. Apoyo y asesoramiento a órganos municipales paraguayos o a la Comisión de Asuntos Municipales de la Cámara de los Diputados en el proceso de transformación legislativo local. Las medidas tendentes a conseguirlo serían:

A) En el plazo de uno o dos años, hasta la consolidación del proceso legislativo democrático municipal con la promulgación o sanción de la reforma de la ley actual o de la nueva Ley Orgánica Municipal, previa la reforma constitucional en este aspecto, desplazamiento de expertos españoles en la temática municipal española, iberoamericana y europea, por períodos de uno o dos meses al año, a determinar por organismos cooperantes españoles y municipalistas paraguayos.

B) Dichos expertos se pondrían a disposición:

a') Del Poder Ejecutivo, para la ayuda en la elaboración del Proyecto de Ley.

b') De la Cámara de Diputados, en el supuesto de que su estadía coincidiera con el período de tramitación por el Poder Legislativo de los proyectos de reformas municipales.

c') De organismos municipalistas paraguayos o municipalidades de importancia para el asesoramiento en lo relativo a la aplicación de los nuevos textos.

El asesoramiento se entiende debe ir encaminado a señalar a los órganos ejecutivos, legislativos o municipalistas de la República de $\mathrm{Pa}$ raguay, cuando así lo requieran, la regulación de instituciones jurídicas en países de América Latina o de la Comunidad Económica Europea.

Los asesores españoles se encuadrarían en los "órganos staff" o de asesoramiento del poder paraguayo de que se tratara, $y$ en orden a responder, informar o dictaminar el tratamiento jurídico internacional que se diera a figuras jurídicas cuya discusión, debate $o$ regulación se fuera a llevar a cabo en las reformas municipales paraguayas.

C) Para ello, deberán disponer de los textos legales de países latinoamericanos y de la C.E. E., así como sólidos conocimientos de 
Derecho Municipal español y del entorno de países aledaños a Paraguay (ver Anexos I y II).

Sin perjuicio de lo anterior:

2.- SEGUNDA. Remisión al Parlamento o a los órganos municipalistas paraguayos de todo tipo de material legislativo que fuera requerido en torno a la regulación de instituciones municipales en España o en el resto de los paises de la C.E.E. , vía Unión de Ciudades Capitales Iberoamericanas (U.C.C.I.). cooperación española (A.E.C.I.), y coordinado todo por el experto o expertos que se designen o institución municipalista que se designara.

3.- TERCERA. Remisión a los mismos organismos de textos legislativos o de instituciones jurídicas municipales comentados de países de América Latina a través de la U. C. C. I. Obviamente, si el Derecho - como ponen de relieve diversos autores- es una técnica, es posible encontrar en un país mejor que en otro, mediante el método comparado, una norma de mayor claridad y eficacia, ya se trate de redactar algunos artículos de una Ley o la totalidad de una institución jurídica.

4.- CUARTA. Capacitación de los Gobiernos Locales.

Para la generación de nuevas autoridades locales se precisa, dado el complejo mundo municipal, la realización de Cursos de Capacitación que se deberían de proyectar en dos frentes:

A) Cursos, seminarios o talleres para futuros Intendentes o miembros de Junta Municipal, Concejales, etc... , y

B) Cursos de capacitación para funcionarios municipales.

Con ayuda española en su financiación y organizado por O. P. A.C. I. o I. D. M. , en colaboración con la Municipalidad de que se tratara o del Departamento donde se desarrollaran, se podrian efectuar Seminarios de Capacitación para futuros Concejales o Intendentes, estudiosos del derecho Municipal y funcionarios con carácter general.

Estos seminarios serían itinerantes y se podrían efectuar en los Departamentos más importantes de la República -en todo caso, propiciando la presencia española en los mismos- bajo el siguiente desarrollo orientativo (con carácter general y a título enunciativo):

DESARROLLO DE SEMINARIOS DE INTENDENTES Y FUNCIONARIOS DIRECTIVOS PARAGUAYOS.

\section{MATERIAS E INTENSIDAD}


- Administración Local paraguaya

- Administración general

- Administración económico-financiera
10 horas

5 horas

5 horas

\section{TEMARIO}

\section{A. Teoría de la Administración Local.}

1.- La Administración Local. Sus relaciones con administración. Tesis comparativas.

2.- El Municipio. Sus antecedentes sociológicos e históricos. Naturaleza y personalidad. Tesis imperante en el mundo.

3.- Contenido de municipio. ¿Político o administrativo?. Elementos que lo integran según doctrina.

4.- Sistema de gobierno local. Concejo abierto. Concejo cerrado. Sistema bicameral. Sistema de comités.

5.- Autoridades municipales. El Alcalde débil. El Alcalde fuerte. El Gerente.

6.- Variedad estructural. Su aplicación en Europa y América. Autoridades periféricas.

7.- Crisis del pequeño municipio. Su modo de solucionarla .

8.- Gobiernos locales en las grandes urbes. Sus problemas y soluciones.

9.- Cooperativismo municipal. La experiencia de Israel, Alemania Oriental y las comunas chinas.

10.- La administración de personal en los gobiernos locales. Sistemas de regulación.

B) Administración Local Paraguaya.

1.- Municipio paraguayo. Su clasificación.

2.- Concejales. Capacidad de hacerlo. Incompatibilidades. Licencias. excusas. Carácter del cargo.

3.- Régimen jurídico y funcionamiento de las Juntas Municipales. Sesiones. Sus clases. Adopción de acuerdos. Trámite en adopción. Responsabilidad de los concejales.

4.- El Intendente. Definición. Antecedentes. Nombramiento. Carácter del cargo. Duración del mandato. Funciones.

5.- Patrimonio municipal paraguayo. Clasificación de los bienes. Privilegios y exenciones. Sus enajenación.

6.- Contratación municipal. Problemas que presenta el reglamento general de licitaciones y contratos de obras públicas.

7.- Urbanización y subdivisión de tierra. Clasificación de las tierras. 
Parcelaciones. Habilitaciones para uso de viviendas. Vías públicas. Normas para su diseño. Instalaciones. Tramitación.

C. Administración general.

1.- Teoría administrativa. Administración. Planificación. Organización. Dirección y control.

2.- Dirección y gestión. decisiones. Mando. Delegación. Coordinación.

3.- Comportamiento organizacional. Organización informal. Relaciones humanas. Motivación. Liderazgo. Dinámica de grupo.

D. Administración económica-financiera.

1.- El Presupuesto. Definición. Evolución de la misma. Clases de Presupuesto. Presupuesto por programas.

2.- El Presupuesto paraguayo Municipal. Concepción. Tramitación y Ejecución. bitrios.

3.- Régimen tributario local. Diversidad de esferas. Impuestos y ar-

4.- Hacia un nuevo sistema de financiación de las municipalidades paraguayas.

QUINTO. INTERCAMBIO DE EXPERTOS Y TECNICOS MUNICIPALES HISPANO-PARAGUAYOS.

Se aprovecharán y se dará la mayor difusión a programas de cooperación que en este sentido se convoquen por Organismos españoles, proyectándolos especialmente al cumplimiento de esta base. Así, en este sentido, se procurará:

a') Que técnicos municipales paraguayos estén presentes, hasta un número de dos a designar por organismos paraguayos, en los Cursos "Comunidad de Madrid" - Unión de Ciudades Capitales Ibero-americanas" que se celebran en Madrid (lo que proporcionaría un convenio C. A. M.-U. C. C. I.-A. E. C. I.).

$\left.b^{\prime}\right)$ Que al menos dos técnicos paraguayos estuvieran incluidos en el Programa de Pasantías en Corporaciones Locales Españolas que organiza el centro de Estudios Municipales y de Cooperación Interprovincial de Granada, en colaboración con A. E. C. I.

c') Difusión en Paraguay de las "Ayudas Quinto Centenario" y de las "Becas Alcalá" sobre investigación municipal.

d') Designación de Intendentes paraguayos para su asistencia a 
encuentros de autoridades municipales españolas e iberoamericanas, organizados por el Centro de Estudios Municipales y de Cooperación Interprovincial de Granada, en colaboración con A. E. C. I.

$\left.e^{\prime}\right)$ Designación de expertos españoles en ciertas cuestiones técnicas municipales (como la depuración de aguas residuales, la eliminación de residuos sólidos, etc.) que visitarían alguna municipalidad paraguaya dentro del programa de Asesorías Técnicas que organizan la Comunidad Autónoma de Madrid (C. A. M.) y la Unión de Ciudades Capitales Iberoamericanas (U. C. C. I.) -lo que propiciaría. como en el caso del anterior apartado $a^{\prime}$ ), un convenio C. A. M.-U. C. C. I.-A. E. C. I.-.

SEXTO. ORGANIZACION DE UN II ENCUENTRO HISPANO-PARAGUAYO DE MUNICIPIOS (U. C. C. I. , O. P. A. C. I.)

Dado el éxito del I Encuentro, una vez promulgada la nueva Ley Orgánica Municipal Paraguaya y trás los comicios electorales municipales, se configuraría la elaboración de la organización de un II Encuentro Hispano-Paraguayo de Municipios, en el que se sintetizaría la experiencia municipal y la solución de las problemáticas municipales paraguayas desde la celebración del I Encuentro. RAGUAY.

SEPTIMO. ORGANIZACION EN MADRID DE LA “SEMANA DEL PA-

Realizada dentro del ciclo de las "Catedras de las Américas" y organizada por U. C. C. I. (mediante el convenio, en su caso, de A. E. C. I. y U.C. C. I.).

OCTAVO. SE INCLUIRA CUALQUIER MEDIDA QUE SE CONSIDERARA OPORTUNA EN ATENCION A LOS REQUERIMIENTOS DE LOS ORGANISMOS PARAGUAYOS.

\section{X.- ALGUNAS REFLEXIONES EN TORNO A LAS FUTURAS MODIFICACIONES LEGISLATIVAS LOCALES EN LA REPUBLICA DE PARAGUAY.}

\section{PRIMERA. ELECCION DIRECTA DE INTENDENTES.}

Elección directa de Intendentes para hacer efectivo el principio de autonomía municipal consagrado en el artículo 17 de la Constitución de la República de Paraguay. 
SEGUNDA. CAMBIO TERMINOLOGICO DEL VOCABLO 'INTENDENTE'.

Siguiendo las recomendaciones de la doctrina municipalista paraguaya, $y$, entre ellos, el profesor LUIS ENRIQUE CHASE PLATE, sustituir la denominación de 'Intendente" (de origen francés) por la de 'Alcalde'.

TERCERA. DEFINICION DEL MUNICIPIO.

El Municipio debe ser considerado huyendo de disquisiciones filosóficas de entidad natural o legal, como célula social de integración y participación del ciudadano en la vida pública para la defensa de los intereses generales.

\section{CUARTA. AUTONOMIA.}

En este sentido, el concepto autonómico necesariamente es lo suficientemente elástico como par permitir traspaso de competencia admitiendo la llamada "competencia compartida", lo que significa la apertura de amplias vías de cooperación de la Administración Local en los servicios del Estado, y la colaboración de éstos en el establecimiento de los servicios propios de las entidades locales.

Se debería delimitar la actuación del Ministerio del Interior en las Municipalidades, relajando las medidas a las que se refiere el artículo 20 de la Ley $n^{\circ}$ 1294. Artículo, por otra parte, criticado por la doctrina municipalista paraguaya.

\section{QUINTA. PARTICIPACION.}

Si la idea de participación es piedra angular en toda la construcción de un régimen local, se deberá dar un nuevo tratamiento a los artículos 75 y siguientes que regulan las "Juntas Comunales de Vecinos" y a los artículos 86 y siguientes de la Ley no 1294, que permitan menos trabas burocráticas para la creación espontánea de asociaciones de vecinos.

\section{SEXTO. CRISIS DEL MUNICIPIO.}

Uno de los problemas más acuciantes en la vida local es la llamada 'crisis del pequeño municipio'. Este suele encontrarse exclusivamente con su elemento territorial, faltándole los otros dos característicos cuales son la población, que emigra a las grandes ciudades y la capacidad económica, que es nula. A este respecto, sugerimos; 
a) Asociación de Municipios.

La figura asociativa es una de las fórmulas que resuelven la crisis municipal, pero entendemos que debe extenderse a la permisión por precepto legal de la llamada asociación imperativa u obligacional, que quiere significar el que cuando el bien común lo requiera, el Gobierno puede obligar a un grupo de municipios o entidades intermedias a crear asociaciones para el mantenimiento de comunes servicios.

b) Asistencia Técnica y Económica.

Uno de los pilares más importantes sobre los que descansa cualquier reforma local, consiste en entender que el municipio, aún el de mayor categoria, carece a veces de elemento humano que pueda planear o llevar adelante un plan de actuación y, sobre todo, de capacidad económica que el permita acometer las obras de infraestructura que todo servicio público requiere.

La serie de congresos realizados para conseguir de los gobiernos la creación de tales entidades, y la existencia de las mismas, tales como FUNDACOMUN en Venezuela, el Banco Municipal en Honduras, el Instituto de Fomento en Guatemala, el Banco Comunal en Bélgica, el banco de Crédito Local en España, etc. , demuestran lo acertado de nuestra conclusión de que se incluya en Ley la creación de una entidad de esta clase.

c) Ayuda estatal a los Municipios.

Dentro de la temática que estamos exponiendo, también resulta ser hecho comprobado el que los municipios, principalmente los económicamente débiles, precisan de la ayuda de los Estados para resolver las necesidades públicas cuya obligación la Ley les impone. Suele ser corriente, y así lo es en Perú, que el Estado ayude a las Haciendas Locales, pero cuando lo hace, lo es en forma de subsidios económicos finalistas que transforman a la entidad en municipios mendicantes.

A resolver tal problema acude la fórmula de destinar un tanto por ciento fijo de los presupuestos estatales, distribuyéndolos por grupos $y$ en razón al número de habitantes, modalidad que viene dando grandes resultados tanto con los llamados fondos europeos (Fondo de perecuación francés o Fondo de Compensación español) como el Situado Constitucional venezolano o en el Situado Fiscal colombiano.

\section{SEPTIMO. COMPETENCIA.}

Nos inclinamos por la llamada exclusión de los paises nórdicos, o sea atribuir a la Administración Local todo lo que no sea competencia del Estado y establecer una competencia obligatoria a efectos de servicios públicos. 


\section{OCTAVO. PROMOCION DE LA ACTIVIDAD PRIVADA.}

Sería perfectamente factible establecer, dentro de la competencia municipal, la promoción de toda clase de actividades que, perteneciendo al ámbito de la autonomía privada o siendo facultad de cualquier otra entidad pública, estén relacionadas con el bien común de la población local.

\section{ANEXO. I. LEGISLACION IBEROAMERICANA.}

- Ley no 19987 (B. 6/12/1972, Orgánica de la Municipalidad de la Ciudad de Buenos Aires.

- Ley de 19 de Diciembre de 1984, Orgánica de Municipalidades de Bolivia.

- Ley de 27 de Diciembre de 1978, Orgánica del Departamento del Distrito Federal de Méjico.

- Ley de 18 de Junio de 1940, Orgánica de los Municipios de Puerto rico.

- Ley $n^{\circ} 6448 / 1977$, sobre Organizaçao política e administrativa dos Municipios dos Territorios Federais, e da outras providencias.

- Ley no 18695, de 31 de Marzo de 1988, de Chile.

- Ley de régimen Municipal de la República de Ecuador.

- Ley de 14 de Junio de 1989, Orgánica de Régimen Municipal de Venezuela.

- Código de régimen Municipal de Colombia, de 26 de Diciembre de 1968.

- Ley de 28 de mayo de 1984, Orgánica de Municipalidades de Perú.

- Ley no 3455, de 14 de Abril de 1981, de Organización Municipal de la República Dominicana.

- Ley no 9515, de 28 de Octubre de 1935, Orgánica Municipal de Uruguay.

- Decreto-Lei no 100/84, de 29 de Março, de Portugal.

- Ley de 28 de Junio de 1988, de Municipios de Nicaragua.

- Ley no 106, de 8 de octubre de 1973, sobre Régimen Municipal de Panamá.

- Decreto no 274, Código Municipal de la república de El Salvador.

ANEXO II. LEGISLACION EUROPEA MUNICIPAL.
A.- BELGICA.

1.- Constitución, 1831. Artículos 108, 108-bis, 108-ter y 109. 
2.- Ley Municipal, de 30 de Marzo de 1836; puesta al día con las sucesivas modificaciones hasta 1 de Septiembre de 1982.

3.- Ley Provincial, de 30 de Abril de 1836; puesta al dia con las sucesivas modificaciones hasta 1 de Septiembre de 1975.

4.- Ley de 1 de marzo de 1922, relativa a la asociación de municipios con fines de utilidad pública; puesta al día con las sucesivas modificaciones hasta 1 de mayo de 1922.

5.- Ley de 23 de Julio de 1971, relativa a la fusión de municipios y modificación de sus límites; puesta al día con las sucesivas modificaciones hasta el 1 de Enero de 1982.

6.- Ley de 26 de julio de 1971, por la que se organizan las agrupaciones y federaciones de municipio; puesta al día con las sucesivas modificaciones hasta el 1 de mayo de 1982.

\section{B.- FRANCIA.}

1.- Constitución, 1958. Artículo 72.

2.- Código Municipal (Decretos 77-90 de 27 de Enero, 77-240 de 7 de Marzo y 77-372 de 28 de Marzo de 1977, que contienen el texto refundido del Código Municipal).

Indice completo. (Se incluyen por la extensión únicamente los siguientes títulos:

Libro I: Título I, II, VI y VII.

Libro II: Completo, excepto el Título VI.

Libro III: Títulos I y II.

Libro IV: Títulos I, II y III.

3.- Ley $n \times 82-213$, de 2 de Marzo de 1982, relativa a los derechos y libertades de los municipios, los departamentos y las regiónes. (Con las modificaciones introducidas por la decisión del Consejo Constitucional de 25 de Febrero de 1982). (Texto traducido al castellano.).

4.- Ley $n^{\circ} 82-623$, de 22 de Julio de 1982, que modifica y completa la Ley $\mathrm{n} \times$ 82-213, de 2 de Marzo de 1982, y que precisa las nuevas condiciones del control administrativo sobre los actos de las autoridades municipales, departamentales y regionales.

5.- Ley $n^{\circ}$ 83-8, de 7 de Enero de 1983, de distribución de competencias entre los Municipios, los Departamentos, las Regiones y el Estado.

\section{C.- GRAN BRETAÑA.}

1.- Ley de 26 de Octubre de 1972, sobre el Gobierno Local. 
D.- ITALIA.

1.- Constitución, 1947. Artículos 5, 114 y 128 a 133.

2.- Real Decreto no 297, de 12 de Febrero de 1911. Texto refundido de la Ley Municipal y Provincial.

3.- Real Decreto no 148, de 4 de Febrero de 1915. Texto refundido de la Ley Municipal y Provincial.

4.- Real Decreto oㅜ 383, de 3 de Marzo de 1934. Texto refundido de la Ley Municipal y Provincial.

5.- Decreto del Presidente de la República no 1, de 14 de Enero de 1971 , de transferencia a las regiones de régimen común de las funciones administrativas estatales, en materia de términos municipales y policía local, urbana y rural, y de su personal respectivo.

6.- Ley $n=278$, de 8 de Abril de 1976 , de descentralización y participación de los ciudadanos en la administración del municipio. 
